\title{
COMUNIDADE DE INIMIGOS NATURAIS E CONTROLE BIOLÓGICO NATURAL DO PULGÃO, APHIS GOSSYPII GLOVER (HEMIPTERA: APHIDIDAE) E DO CURUQUERÊ, ALABAMA ARGILLACEA HÜBNER (LEPIDOPTERA: NOCTUIDAE) NA CULTURA DO ALGODOEIRO NO DISTRITO FEDERAL
}

\author{
E.R. Sujiii ${ }^{1}$, V.A. Beserra ${ }^{2}$, P.H. Ribeiro' ${ }^{2}$ P.V. da Silva-Santos ${ }^{2}$, \\ C.S.S. Pires ${ }^{1}$, F.G.V. Schmidt ${ }^{1}$, E.M.G. Fontes ${ }^{1}$, R.A. Laumannn ${ }^{1}$
}

${ }^{1}$ Embrapa Recursos Genéticos e Biotecnologia -Cenargen, Parque Estação Biológica - PqEB Final W5 norte, CEP 70770-900, Brasília, DF, Brasil. E-mail: sujii@cenargen.embrapa.br

\section{RESUMO}

\begin{abstract}
O uso intensivo de inseticidas químicos é uma prática comum que pode causar o aumento na abundância de pragas devido ao desequilíbrio resultante da destruição de inimigos naturais e redução do controle biológico natural. Visando avaliar o controle biológico natural em algodoeiros no Distrito Federal na safra 2004/2005, predadores do pulgão, Aphis gossypii (Hemiptera: Aphididae) e parasitóides da lagarta curuquerê, Alabama argillacea(Lepidoptera: Noctuidae), foram identificados e avaliados/5. As avaliações foram realizadas em diferentes áreas de plantio e sob diferentes métodos de controle de pragas (inseticidas químicos, microbianos e controle). Cinco espécies de joaninhas, Cycloneda sanguinea, Scymnus sp., Hippodamia convergens, Eriopis conexa e Olla v-nigrum, a tesourinha, Doru cf. luteipes, a mosca Condylostylus sp. (Dolichopodidae) e várias espécies de aranhas foram os predadores mais abundantes de pulgões. Não houve diferença na riqueza de espécies nas áreas estudadas. Foi observada correlação positiva e significativa entre as populações de pulgões e alguns grupos de predadores apenas no tratamento com inseticidas biológicos, indicando possível resposta numérica do predador na ausência de inseticidas químicos de largo espectro. O uso de inseticidas químicos controlou satisfatoriamente a população de lagartas apenas na primeira geração, o que pode estar relacionado à menor incidência de parasitismo neste tratamento $(2,20 \pm 1,40 \%)$ quando comparado com a testemunha $(23,90 \pm 9,50 \%)$. Não foram observados efeitos deletérios de inseticidas biológicos nas taxas de parasitismo $(5,80$ $\pm 1,87 \%$ ) em relação à testemunha. Os parasitóides encontrados pertencem às ordens Diptera (Tachinidae e Phoridae) e Hymenoptera (Encyrtidae, Eulophidae, Chalcididae. Ichneumonidae e Braconidae).
\end{abstract}

PALAVRAS-CHAVE: Pragas do algodoeiro, entomofauna, parasitóides, predadores, controle populacional.

\section{ABSTRACT}

COMMUNITY OF NATURAL ENEMIES AND NATURAL BIOLOGICAL CONTROL OF THE APHID APHIS GOSSYPII GLOVER (HEMIPTERA: APHIDIDAE) AND COTTON LEAFWORM ALABAMA ARGILLACEA HÜBNER(LEPIDOPTERA: NOCTUIDAE) INTHECOTTONCROP.The intensive use of chemical pesticides has been a common practice among farmers which leads to increases in the abundance of pests due the disturbances caused by the mortality of natural enemies and reduction of biological controls. Aiming to evaluate the natural biological control in cotton crops on the Distrito Federal, Brazil, predators of the cotton aphid Aphis gossypii (Hemiptera: Aphididae) and parasitoids of the cotton leaf worm Alabama argillacea (Lepidoptera: Noctuidae) were identified and evaluated during 2004/2005. Evaluation was done on cotton crops located in different areas and managed with different pest-control methods (chemical insecticides, microbial insecticides and control). Five species of ladybeetles, Cycloneda sanguinea, Scymnus sp., Hippodamia convergens, Eriopis conexa and Olla v-nigrum, as well as the earwig Doru cf.luteipes and predator fly Condylostylus sp. (Dolichopodidae) and several other species of spider were observed as the most abundant predators of aphids. There was no difference in the predator species richness within the

\footnotetext{
${ }^{2}$ Universidade Católica de Brasília, Departamento de Biologia, Taguatinga, DF, Brasil.
} 
studied areas. There was a positive and significant correlation between predator species and the density of aphids in the biological insecticides treatment, suggesting a possible numerical response of predators in the absence of broad-range chemical insecticide use. Chemical pesticides offered satisfactory control only for the first generation of the cotton leaf worm A. argillacea. This finding could be related to a parasitism incidence in this treatment $(2.2 \pm 1.40 \%)$ against the control $(23.9 \pm$ $9.50 \%)$. A disruption effect in parasitism was not observed in the biological control area $(5.8 \pm 1.87 \%)$ when compared with the control. Parasitoids were found in the orders Diptera (Tachinidae, Phoridae) and Hymenoptera (Encyrtidae, Eulophidae, Chalcididae, Ichneumonidae, and Braconidae).

KEY WORDS: Cotton pests, entomofauna, parasitoids, predators, population control.

\section{INTRODUÇÃO}

A cultura do algodoeiro abriga cerca de 30 espécies de artrópodes fitófagos considerados pragas (GAllo et al., 2002; SujII et al., 2006) e dentre as que atacam a parte aérea do algodoeiro, na região do Distrito Federal, destacam-se o pulgão Aphis gossypii (Glover, 1877) (Hemiptera: Aphididae), e a lagarta curuquerê Alabama argillaceae (Hübner, 1818) (Lepidoptera: Noctuidae) como as principais pragas da fase inicial ou vegetativa.

Diversos inseticidas químicos são usados visando minimizar os danos causados pelas pragas e é usual a aplicação de diversos ingredientes ativos em 6 a 18 aplicações por safra, número que varia com a região de plantio e a intensidade de ocorrência de insetos em diferentes anos (FonTEs et al., 2006). O uso intensivo de inseticidas químicos para o controle das pragas do algodoeiro, geralmente sem considerar sua seletividade a inimigos naturais de pragas presentes na cultura, pode causar surtos de pragas secundárias e ressurgência de pragas principais (CAMPos et al., 1986). A preservação e manutenção dos inimigos naturais são imprescindíveis para estabelecer o equilíbrio biológico e reduzir os custos de produção (Gravena, 1983). Dentre os inimigos naturais, as joaninhas (Coccinellidae) apresentam grande destaque, pois a maioria de suas espécies é entomófaga e suas larvas eadultos apresentam grande diversidade de presas, alimentando-se de pulgões, ácaros e larvas de coleópteros desfolhadores (CLAusen, 1972; HodeK, 1973). Asprincipaisespécies dejoaninhas predadoras (Coleptera: Coccinelidae) presentes na cultura do algodão são: Cycloneda sanguinea (L., 1763); Eriopis connexa (Germar, 1824);Hippodamia convergens (Guérin Méneville, 1842); Coleomegillamaculata (DeGeer, 1775); Olla v-nigrum (Mulsant,1866); Hyperaspis festiva (Mulsant, 1850) e Scymnus sp. (SILVIE et al., 2001). Estudo realizado por RAMALHOet al.(1990) mostraram que o complexo de espécies de inimigos naturais (joaninhas, aranhas e sirfídeos) existente no agroecossistema do algodoeiro é capaz de exercer ação de controle sobre o pulgão $A$. gossypii, chegando a manter as populações desta praga em níveis relativamente baixos, sem a necessidade de aplicações de inseticidas. Além dos coccinelídeos, outros predado- res como crisopídeos, sirfídeos, tesourinhas e aranhas atuam como importantes predadores de pulgões e de ovos e lagartas de lepidópteros. Além dos predadores, parasitóides de diversas famílias da ordem Hymenoptera e larvas de taquinídeos da ordem Diptera são citados como inimigos naturais do pulgão do algodoeiro e de lagartas que ocorrem naquela cultura (Gondim et al., 2001, Gravena, 1983).

A abundância de aranhas e de insetos e ácaros predadores será menor caso a população de presas herbívoras seja reduzida, o que poderá potencialmente interferir com a diversidade dentro das cadeias alimentares, inclusive aquelas das áreas ao redor dos campos agrícolas. Este tipo de efeito ecológico foi observado a partir do uso indiscriminado de inseticidas ou do plantio em grandes áreas contínuas de variedades altamente resistentes a determinados tipos de insetos (Hoy et al., 1998). O uso intensivo de inseticidas químicos para o controle de pragas-chave freqüentemente causa distúrbios nas cadeias tróficas que previnem a explosão populacional de pragas secundárias, alterando interações importantes na regulação populacional de espécies fitófagas.

Visando reduzir o impacto causado pela aplicação de inseticidas químicos, novas estratégias de manejo, que utilizam métodos alternativos como controle biológico e plantas geneticamente modificadas resistentes a insetos, deverão ser propostas e avaliadas. Essas tecnologias também deverão ter seu impacto ecológico avaliado para que a cultura se desenvolva em bases sustentáveis.

O objetivo do presente estudo foi identificar a comunidade de inimigos naturais do pulgão do algodoeiro e da lagarta do curuquerê na região do Distrito Federal e o impacto do uso de inseticidas na abundância dessas espécies.

\section{MATERIAL E MÉTODOS}

O presente estudo foi desenvolvido em dois campos experimentais: o primeiro, comárea de 0,1 ha sem o controle de pragas visando identificar a fauna de artrópodos predadores presentes no algodoeiro, foi plantado e conduzido na Embrapa Recursos Genéticos e Biotecnologia (Cenargen) e, o segundo, com área 
de 0,4 ha, na área experimental da Embrapa Hortaliças (CNPH), onde parcelas tratadas com inseticidas químicos foram comparadas com aquelas tratadas com inseticidas biológicos e com parcelas testemunha que não receberam nenhum tratamento contra pragas (4 parcelas/tratamento). A variedade dealgodoeiro Delta Opal foi plantada nas duas áreas com espaçamento de um metro entre linhas 8 a 10 plantas por metro linear. No Cenargen, o plantio foi feito em 18/11/2004, com emergência das plantas no dia 24/ 11 e, no CNPH, o plantio deu-se em 6/12/2004, com emergência das plântulas a partir de 11/12. O solo foi corrigido e adubado com fertilizantes químicos e as plantas invasoras controladas com o uso de herbicidas diuron em pré-emergência e glufosinato em pós-emergência e capina manual.

$\mathrm{Na}$ área experimental do $\mathrm{CNPH}$, as quatro parcelas de cada tratamento foram sorteadas totalmente ao acaso. Uma das parcelas a ser tratada com inseticida biológico foi perdida devido à grande população de plantas invasoras. Os inseticidas químicos utilizados no experimento tinham os seguintes ingredientes ativos: diafentiuron, imidacloprido, metamidofós e cipermetrina + fenofós e foram aplicados na dosagem recomendada pelo fabricante quando as densidades das pragas atingiram os níveis de controle prescritos por GoNDIM etal. (2001) nos dias 20/1, 24/3 e 21/4. Os inseticidas biológicos utilizados na área foram Beauveria bassiana + Verticillum lecaniii $(4+4 \mathrm{~kg} / \mathrm{ha}$ na concentraçãode 5,0 $010^{12}$ esporos) para o controle de pulgões e Bacillus thuringiensis (1,5 L/ha de produto comercial Dipel $\left.{ }^{\circledR}\right)$ para o controle da lagarta do curuquerê, Alabama argillacea nos dias 27/1, 31/3 e $27 / 4$.

As amostragens de pragas e seus inimigos naturais foram realizadas semanalmente e se iniciaram duas semanas após a germinação das plântulas, quando estas apresentavam de 4 a 6 folhas expandidas. Todas as plantas naárea do Cenargene 20 plantas por parcela na área experimental do CNPH foram vistoriadas e todos os pulgões e seus predadores encontrados foram registrados. No $\mathrm{CNPH}$, foram realizadas 3 amostragens/parcela/data quando foram registradas as lagartas presentes em unidade amostral de $1 \mathrm{~m}$ linear da cultura. As lagartas coletadas foram criadas em laboratório em recipientes plásticos de $500 \mathrm{~mL}$, utilizando folhas de algodão comoalimento e observadas diariamente até a eclosão dos adultos ou de parasitóides. Os parasitóides obtidos foram conservados em álcool $70 \%$ para posterior identificação das famílias e separação em morfoespécies.

As estruturas das comunidades de predadores nas áreas do Cenargen e do CNPH foram comparadas com base nas riquezas de espécies, analisadas pelas curvas de rarefação, e a diversidade estimada pelo índice de Shannon-Wienner (KREBS, 1998) e compara- das pelo teste $t$ (ZAHR, 1999). A similaridade das comunidades de predadores nas parcelas sob diferentes métodos demanejoforam comparadas, aos pares, pelo índice de Morisita (KREBS, 1998). A abundância de cada espécie ou grupo de predadores foi correlacionada pelocoeficientedePearson coma abundância semanal de pulgões, visando determinar as relações de dependência de densidade e comparada por análise de variância não-paramétrica (ZHAR., 1999).

\section{RESULTADOS E DISCUSSÃO}

A fauna de predadores no Cenargen apresentou predominância de joaninhas (Coleoptera: Coccinelidae) que representaram 53,8\% dos indivíduos coletados; Cycloneda sanguinea e Scymnus spp. foram as espécies mais abundantes (Tabela 1), assim como moscas predadoras (Diptera: Dolichopodidae) e aranhas. No Mato Grosso doSul (BArros et al.,2006) e em São Paulo (CAMPOs et al., 1986; RAMIRO \& FARIA 2006), foi observada maior abundância de coccinelídeos predadores e sua associação com populações de A. gossypii. As observações do presente estudo e os dados da literatura demonstram a distribuição desses predadores pelas regiões produtoras do Centro Sul do país e sua importância no controle biológico natural no algodoeiro. SouzA (2004) estudou a dinâmica populacional de quatro diferentes espécies de afídeos e verificou que aranhas, Cycloneda sanguinea, Lebia concinna e Diaeretiella rapae, são os inimigos naturais com maior potencial de controle das populações dos pulgões.

$\mathrm{Na}$ área do $\mathrm{CNPH}$, a espécie mais abundante foi Doruluteipes (Scudder,1876)(Dermaptera:Forficulidae), juntamente com as mesmas espécies observadas no Cenargen. Tal abundância de D. luteipes no CNPH provavelmente se deve à presença de um plantio de milho na área vizinha. De modo geral, as estruturas das comunidades de espécies predadoras de pulgões nas duas áreas apresentaram semelhanças na composição e riqueza de espécies. As curvas de rarefação para as áreas do Cenargen e CNPH (Fig. 1A) indicam que a riqueza esperada de espécies é equivalente para o mesmo número de indivíduos. O coeficiente de similaridade entre áreas foi de $61 \%$, calculado pelo índice de Morisita. O índice de Shannon-Wiennner apresentou diversidade mais elevada no $\mathrm{CNPH}$ em relação ao Cenargen ( $t=2,071882$ g.l. $p<0,05)$ (Tabela 1). É possível que as diferenças observadas nas diversidades dos locais reflitam a influência de características do entorno do plantio na estruturação dessas comunidades. Aárea do Cenargen está próxima a uma área de cerrado, enquanto que a do CNPH era por um lado margeada por uma mata galeria de um dos ladose, por outro, por um plantio de milho. 
Tabela 1 - Abundância relativa de espécies ou grupos de predadores coletados em diferentes áreas de algodoeiro no Distrito Federal.

\begin{tabular}{|c|c|c|c|c|}
\hline \multirow[t]{2}{*}{ Predadores } & \multicolumn{2}{|c|}{ Cenargen } & \multicolumn{2}{|c|}{$\mathrm{CNPH}$} \\
\hline & Indivíduos & Percentagem & Indivíduos & Percentagem \\
\hline Cycloneda sanguinea & 304 & 32,7 & 112 & 9,3 \\
\hline Scymnus spp. & 112 & 12,0 & 149 & 12,4 \\
\hline Hippodamia convergens & 48 & 5,2 & 4 & 0,3 \\
\hline Eriopis connexa & 37 & 4,0 & 9 & 0,7 \\
\hline Olla v-nigrum & 0 & 0 & 2 & 0,2 \\
\hline Doru luteipes & 28 & 3,0 & 363 & 30,2 \\
\hline Araneae & 127 & 13,6 & 280 & 23,3 \\
\hline Chrysopidae & 2 & 0,2 & 64 & 5,3 \\
\hline Syrphidae & 16 & 1,7 & 42 & 3,5 \\
\hline Dolichopodidae & 252 & 27,1 & 171 & 14,2 \\
\hline Orius insidiosus & 5 & 0,5 & 5 & 0,4 \\
\hline Índice Shannon-Wienner $\left(\mathrm{H}^{\prime}\right)$ & 2,52 & & 2,63 & \\
\hline
\end{tabular}

Tabela 2 - Abundância de predadores de pulgão nas quatro parcelas tratadas em cada método de manejo de pragas na área experimental da Embrapa Hortaliças (CNPH).

\begin{tabular}{lrrr}
\hline Predadores & Químico & Biológico & Testemunha \\
\hline Cycloneda sanguinea & 34 & 41 & 37 \\
Scymnus spp. & 96 & 28 & 25 \\
Hippodamia convergens & 2 & 2 & 0 \\
Eriopis connexa & 5 & 2 & 2 \\
Olla v-nigrum & 0 & 1 & 1 \\
Doru luteipes & 127 & 104 & 132 \\
Araneae & 80 & 86 & 114 \\
Chrysopidae & 17 & 15 & 32 \\
Syrphidae & 23 & 8 & 11 \\
Dolichopodidae & 48 & 54 & 69 \\
Orius insidiosus & 1 & 2 & 2 \\
Indice Shannon- & 2,52 & 2,58 & 2,63 \\
Wienner $\left(\mathrm{H}^{\prime}\right)$ & & & \\
\hline
\end{tabular}

A aplicação de diferentes métodos de controle de pragas no $\mathrm{CNPH}$, que supostamente deveria produzir um gradiente de impactos na fauna de predadores, aparentemente não produziu o efeito esperado já que a fauna observada manteve proporções semelhantes deabundância de predadores (Tabela 2). As curvas de rarefação indicam que não houve diferenças na riqueza de espécies entre os tratamentos para abundâncias equivalentes de indivíduos coletados em função da sobreposição dos desvios padrão(Fig.1B). Oíndice de Shannon-Wienner também não apresentou diferenças significativas como medida da diversidade de predadores entre os tratamentos quando comparados aos pares pelo teste t. Apenas os coeficientes de similaridade das comunidades de predadores (Tabela 3), calculados pelo índice de Morisita, reproduzi-
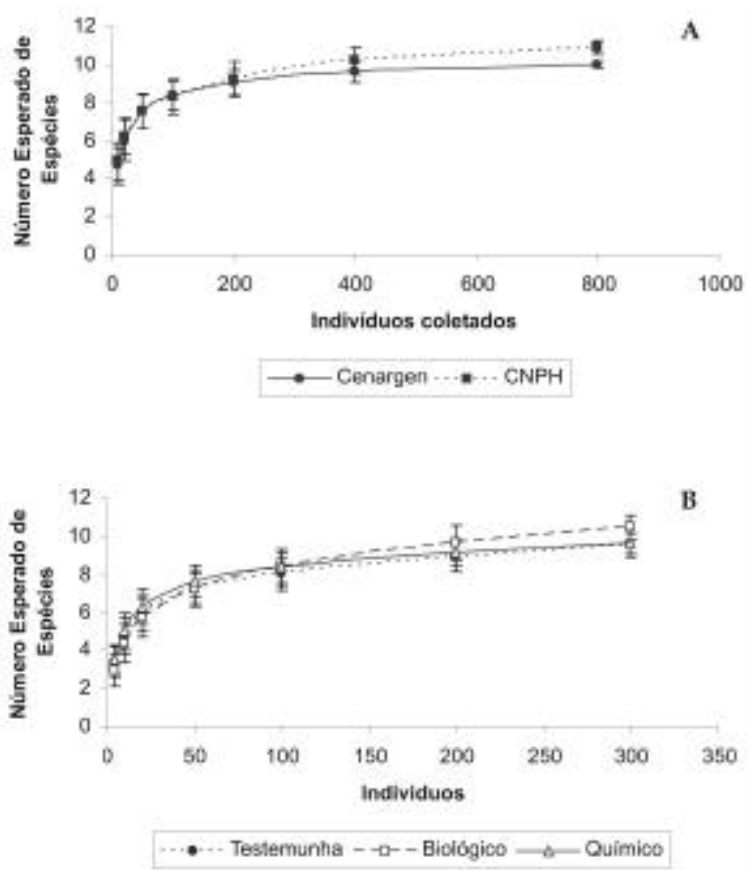

Fig. 1 - Curva de rarefação estimando o número de espécies de predadores \pm desvio padrão em função do número de indivíduos coletados em (A) diferentes áreas plantadas com algodoeiro no Distrito Federal. (B) áreas submetidas a diferentes métodos de controle de pragas em plantio de algodoeiro na Embrapa Hortaliças, DF.

ram o gradiente de impacto na diversidade de predadores em razão dos métodos de controle químico, biológico e testemunha, com maior diferença entre as comunidades submetidas a inseticidas químicos em relação à testemunha; sendo que a comunidade submetida aos inseticidas biológicos ocupou uma posição intermediária. A ausência de diferença na riqueza e diversidade de espécies entre os tratamentos pode 
ser devida à distribuição regular das chuvas, que reduziu o crescimento populacional do pulgão (Fig. 2). Esse fenômeno manteve a proporção de plantas atacadas abaixo do limiar de controle na maior parte do período, mesmo nas áreas testemunhas. A conseqüência da baixa infestação das plantas por pulgões foi um maior espaçamento das aplicações de inseticidas químico e biológico. Além disso, as chuvas constantes afetam a ação residual de produtos de contato, como piretróides e fungos entomopatogênicos, que são lavados da superfície das folhas. O padrão observado no coeficiente de similaridade entre as comunidades de predadores apóia a hipótese de que houve baixo impacto causado pelos inseticidas devido aos fatores acima citados. Adicionalmente, a elevada capacidade de dispersão e redistribuição entre áreas pelos predadores, e a baixa densidade da presa afetando a colonização por predadores em processos dependentes da densidade podem ter minimizado as diferenças entre as comunidades observadas.

A correlação, calculada pelo coeficiente de Pearson, entre os grupos ou espécies de predadores amostrados semanalmente e a percentagem de plantas atacadas por pelo menos 1 pulgão ou colônias de 5 ou mais pulgões foi em geral baixa e não significativa. No entanto, as amostragens de joaninhas $(\mathrm{r}=$ $0,75 \mathrm{p}=0,03)$, dolicopodídeos $(\mathrm{r}=0,71 \mathrm{p}=0,05)$ e sirfídeos $(r=0,74 p=0,04)$ mostraram-se
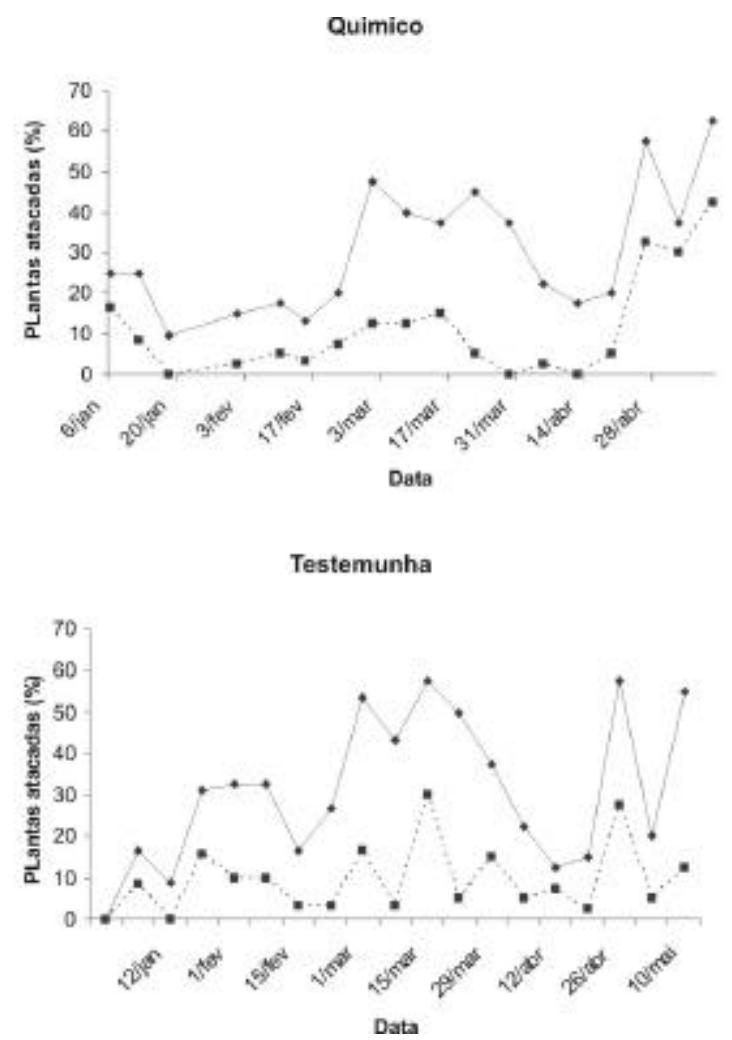

correlacionadas com a percentagem de plantas atacadas por colônias de 5 ou mais pulgões no tratamento com inseticidas biológicos, e dolicopodídeos $(r=0,75$ $\mathrm{p}=0,03)$ e sirfídeos $(\mathrm{r}=0,87 \mathrm{p}=0,01)$ nos tratamento controle para plantas atacadas por pelo menos um pulgão. Esse resultado sugere que, apesar deRAMALHO et al. (1990) citarem os predadores polífagos e generalistas como um importante fator de mortalidade da praga, estes não são capazes de regular as populações de A. gossypii, evitando oscilações bruscas e explosões populacionais. Porém, predadores mais especializados, como dípteros ejoaninhas, apresentaram correlações significativas e elevadas quando não expostos aos inseticidas químicos, mostrando que esses predadores podem responder numericamente ao aumento da infestação por pulgão no algodoeiro e controlar suas populações.

Tabela 3 - Coeficiente de similaridade (\%) calculado pelo índice de Morisita para a comunidade de predadores de pulgão entre tratamentos para manejo de pragas em área de algodão na Embrapa Hortaliças (CNPH).

\begin{tabular}{lccc}
\hline Tratamentos & Testemunha & Biológico & Químico \\
\hline Testemunha & 1 & 0,99 & 0,91 \\
Biológico & & 1 & 0,94 \\
Químico & & & 1 \\
\hline
\end{tabular}

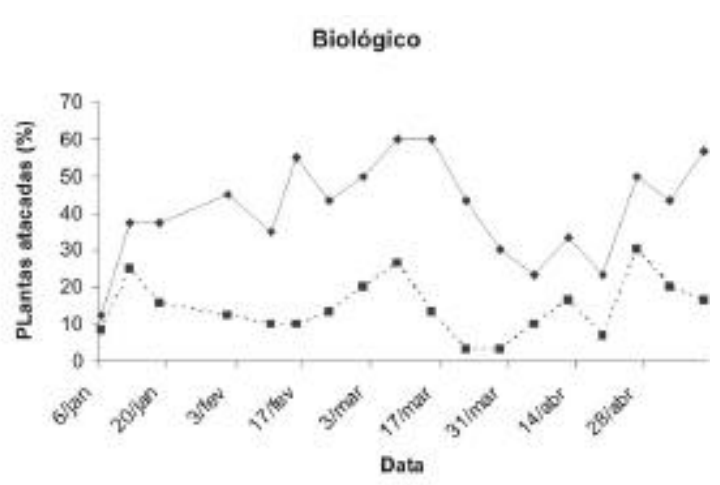

Fig. 2 - Plantas atacadas pelo pulgão, A phis gossypii, em plantio de algodoeiro tratado com diferentes métodos de controle de pragas - Químico, Biológicos e Testemunha (sem aplicação de produtos), em 2005, na Embrapa Hortaliças, DF. 


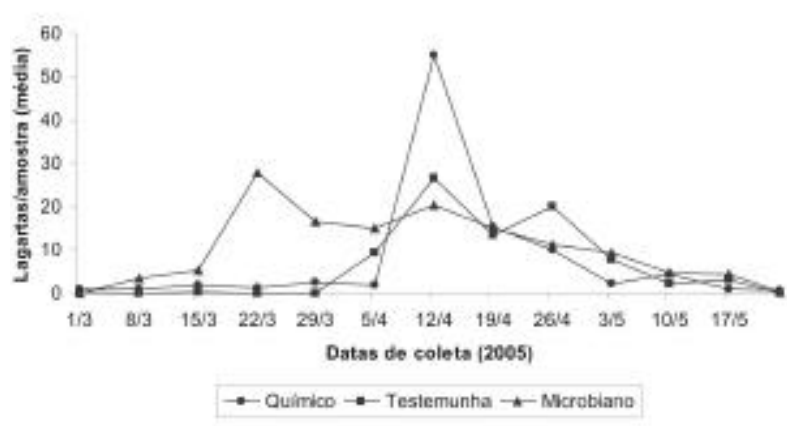

Fig. 3 - Flutuação populacional de lagartas de A. argillacea coletadas (amostras de $1 \mathrm{~m}$ linear de plantas) em parcelas de algodoeiro submetidas a diferentes métodos de controle de pragas na região do Distrito Federal.

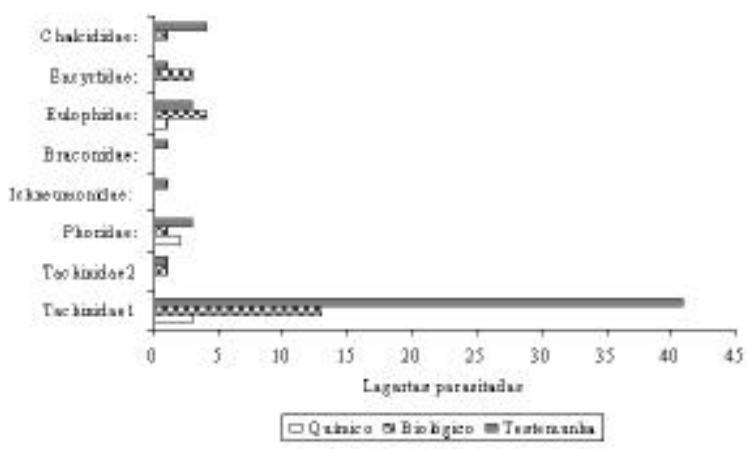

Fig. 4 - Riqueza de parasitóides e abundância relativa de lagartas parasitadas de $A$. argillacea, encontradas em cultivos de algodoeiro, com diferentes manejos de pragas em 2005, na região do Distrito Federal.

Tabela 4 - Posição taxonômica e características biológicas dos parasitóides encontrados em lagartas de A. argillacea.

\begin{tabular}{ll}
\hline Ordem/Família/Morfoespécie & Características biológicas \\
\hline Diptera & \\
Tachinidae Morfoespécie 1 & solitário, endoparasitóide, idibionte ${ }^{1}$ \\
Tachinidae Morfoespécie 2 & $\begin{array}{l}\text { solitário, endoparasitóide, idibionte } \\
\text { gregário, endoparasitóide, cenobionte }{ }^{2}\end{array}$ \\
Phoridae Morfoespécie1 & \\
Hymenoptera & gregário, endoparasitóide, cenobionte \\
Ichneumonidae Morfoespécie 1 & gregário, endoparasitóide, cenobionte \\
Braconidae Morfoespécie 1 & gregário, ectoparasitóide, cenobionte \\
Eulophidae Morfoespécie 1 & gregário, endoparasitóide, cenobionte \\
Encyrtidae Morfoespécie 1 & solitário, endoparasitóide, idibionte \\
Chalcididae Morfoespécie 1 &
\end{tabular}

${ }^{1}$ Paralisa o hospedeiro e impede seu desenvolvimento após o parasitismo.

${ }^{2} \mathrm{O}$ hospedeiro continua se desenvolvendo após o parasitismo.

Tabela 5 - Comparação da taxa de parasitismo (\% lagartas parasitadas) em parcelas de algodoeiro tratadas com diferentes métodos de controle de pragas, na região do DistritoFederal, por análise de variância não-paramétrica (Kruskal-Wallis H: 9,79 gl=2 p=0,007). Médias seguidas pela mesma letra não diferem significativamente (teste de Dunn $\mathrm{p}<0,05)$.

\begin{tabular}{lcc}
\hline Tratamento & Média $(\%)$ & \pm desvio padrão \\
\hline Testemunha & 23.9 & $\pm 8.02 \mathrm{a}$ \\
Biológico & 5.8 & $\pm 1.73 \mathrm{~b}$ \\
Químico & 2.2 & $\pm 1.30 \mathrm{c}$ \\
\hline
\end{tabular}

O controle biológico natural das populações de pulgões no algodoeiro, exercido por predadores e parasitóides, é um componente importante no manejo de pragas em países como Austrália (WILson et al., 2003) e EUA (BACHELER, 2005). Nesses países, o uso de produtos seletivos a inimigos naturais, além da escolha de variedades resistentes ao pulgão, visa preservar o controle biológico natural e impedir o aumento das populações do pulgão (WILsON et al., 1999).

Estudos de interação predador/presa, entre as espécies que apresentaram correlação positiva com a infestação do pulgão, deverão ser realizados para avaliar o papel e o potencial de cada um como agente de controle biológico natural. No entanto, esse trabalho apresenta indicações, apoiadas por dados de literatura (CONWAY etal., 2006), de que o estabelecimento de níveis de não-ação na presença de inimigos naturais e o uso de inseticidas biológicos ou químicos seletivos são essenciais para o aumento na eficiência do controle do pulgão do algodoeiro.

Nas condições ecológicas da região do $\mathrm{CNPH}, A$. argillacea apresenta duas gerações (Fig. 3). A aplicação de inseticidas químicos controlou eficientemente apenas a primeira geração de lagartas (Fig. 3). Contudo, a segunda geração apresentou maior densidade de indivíduos, o que pode ser resultado do impacto desse método de controle nos inimigos naturais, que 
são importantes agentes de controle de lagartas em cultivos de algodão (SILVIE et al., 2001).

Os diferentes métodos de controle influenciaram significativamente a diversidade de parasitóides de lagartas de $A$. argillacea presentes na área experimental do CNPH. Maior riqueza de morfoespécies foi encontrada nas parcelas testemunha, que não receberam tratamentos para controle de pragas (Fig. 4). A posição sistemática e as principais características biológicas dos parasitóides, encontrados nas parcelas sem tratamento contra pragas, são apresentadas na Tabela 4. Destas, apenas uma morfoespécie das famílias Tachinidae, Phoridae e Eulophidae foram também encontradas nas parcelas com tratamento químico. Silvie et al. (2001) também registraram parasitóides de lagartas de algodão das ordens Hymenoptera e Diptera. Neste trabalho, são mencionados parasitóides das famílias Braconidae, Eulophidae, Encyrtidae e Tachinidae. A espécie mais abundante, com $50 \%$ ou mais dos registros totais dos parasitóides recuperados das lagartas criadas no laboratório, foi a morfoespécie 1 de Tachinidae(Fig. 4).

A abundância de parasitóides, expressa através da porcentagem média de lagartas parasitadas, foi significativamente afetada pelo controle químico (Tabela 5). A baixa incidência de parasitóides no controle químico pode explicar o maior pico delagartas encontrado na segunda geração ao ser comparado com os outros manejos avaliados (Fig. 3).

Silva et al. (1997) encontraram que, para os parasitóides de Spodoptera frugiperda (Smith), o taquinídeo Archytas incertus (Macquart) se desenvolvia nos ínstares finais ( $5^{\circ}$ e $6^{\circ}$ ínstares e pupas), enquanto que os himenópteros parasitóides, nos ínstares iniciais $\left(2^{\circ}\right.$ e $\left.3^{\circ}\right)$. Os dípteros parasitóides possuem preferência pelos ínstares finais do hospedeiro devido a sua maior exigência alimentar, pois quando o parasitismo ocorre nos primeiros ínstares larvais, os dípteros não atingem a fase adulta, por não encontrarem alimento suficiente no hospedeiro; por outro lado, os himenópteros apresentam exigências nutricionais diferentes (Notz, 1972 apud. Silva et al., 1997). O fato das moscas Tachinidae terem preferência pelos ínstares larvais mais tardios pode explicar a recuperação de maior quantidade de lagartas parasitadas por dípteros no presente estudo. Além disso, as fases mais juvenis das lagartas são mais susceptíveis à ação dos inseticidas, possivelmente os himenópteros que parasitam osínstares mais iniciais serão mais afetados por inseticidas que os taquinídeos devido à mortalidade das lagartas.

Esta diferença na fauna de inimigos naturais coincide com o observado em outros trabalhos para diversos parasitóides de pragas da cultura de algodão como, por exemplo, moscas-brancas (Hemiptera: Aleyrodidae) NARANjo \& AKEY, 2005) e afídeos
(Hemiptera: Aphididae) (KeRns \& GAYLOR, 1993), que normalmente são afetados seriamente por inseticidas não seletivos e/ou de uso intensivo.

Os resultados obtidos indicam que tanto a abundância como a estrutura da guilda de parasitóides que atacam $A$. argillacea podem ser afetadas pelo uso de inseticidas, efeito também encontrado em comunidades de insetos benéficos (predadores e parasitóides) em culturas de algodão da Austrália (MANSFIELD et al., 2006).

\section{REFERÊNCIAS}

BACHELER, J.S. Managing insects on cotton. In: North Caroline Cooperative Extension. 2006 Cotton Information, North Carolina State University, Raleigh, 2006. cap.11 p.133-158. Disponível em ४http:// ipm.ncsu.edu/Production_Guides/Cotton/chptr11. pdf >. Acesso em: 5 dez. 2006.

Barros, R.; Degrande, P.E.; Ribeiro, J.F.; Rodrigues, A.L.L.; NogueIra, R.F.; Fernandes, M.G. Flutuação populacional de insetos predadores associados a pragas do algodoeiro. Arquivos do Instituto Biológico, São Paulo, v.73,n.1, p.57-64, 2006. Disponívelem: < http://www. biologico.sp.gov.br/ARQUIVOS/V73_1/barros. PDF>. Acesso em: 5 dez. 2006.

Campos, A.R.; Gravena, S.; Bertozo, R.; Barbieri, J. Artrópodes predadores na cultura algodoeira e comparação de métodos de amostragem. Anais da Sociedade Entomológica do Brasil, Londrina, v.15, p.5-20, 1986.

Clausen, C.P. Entomophagous insects. London: Hafner Publishing Company, 1972. 688p.

Conway, H.E.; Steinkraus, D.C.; Kring, T.J. Experimental treatment threshold for the cotton aphid (Homoptera: Aphididade) using natural enemies in Arkansas cotton. Journal of Entomological Science, v.41, n.4, p.361373, 2006.

FonTES, E.F.; Ramalho, F.S.; UnderwoOd, E.; B ARROSO, P.A.V.; SimON,M.F.;S ujII, E.R.;P IRES, C.S.S.; Beltrão, N.; LucENA W.A.; FreIRE E.C. The cotton agriculture context in Brazil. In: Hilbeck, A.; Andow, D.A.; Fontes, E.M.G. (Eds.). Environmental risk assessment of genetically modified organisms volume 2 methodologies for Assessing Bt Cotton in Brazil. Wallingford: CABI Publishing, 2006. p.21-66

Galo, D.; Nakano, O.; Carvalho, R.P.L.; De Baptista, G.C.; Berti Filho, E.; Parra, J.R.P. ; Zucchi, R.A.; Alves, S.B.; Vendramin, J.D.; Marchini, L.C.; Lopes, J.R.S.; Омото, C. Entomologia Agrícola. Piracicaba: Fealq, 2002. 920p.

Gondim, D.M.C.; Belot, J.L.; Silvie, P.; Petit, N. Manual de indentificação das pragas, doenças, deficiências minerais e injúrias do algodoeiro do Brasil.3ed. Cascavel: Codetec/ CIRAD, 2001. 120p. (Boletim Técnico, 33).

GravenA, S. O controle biológico na cultura algodoeira. Informe Agropecuário, v.9, p.3-15, 1983.

HodeK, I. Biology of Coccinellidae. Prague: Academic of Sciences, 1973. 260p. 
Hoy, C.W.; Feldman, J.; Gould, F.; Kennedy, G.G.; Reed, G.; WYMAN, J.A. Naturally occurring biological controls in genetically engineered crops. In: BARBOSA, P. (Ed.). Conservation biological control. San Diego: Academic Press, 1998. cap.10, p.185-205.

Kerns, D.L.; Gaylor, M.J. Biotic control of cotton aphid (Homoptera: Aphididae) in cotton influenced by insecticides. Journal of Economic Entomology, v.86, p.18241834. 1993.

Krebs, C.J. Ecological Methodology. Menlo Park, Addison Wesley, 1998. 620p.

Mansfield, S.; Dllon, M.L.; Whitehouse, M.E.A. Are arthropod communities in cotton really disrupted? An assessment of insecticide regimes and evaluation of the benefical disruption index. Agriculture, Ecossystems and Environment, v.113, p.326-335, 2006.

NARANJO,S.E.; A KEY, D.H. Conservation of natural enemies in cotton: comparative selectivity of acetamiprid in the management of Bemisia tabaci. Pest Management Science, v.6, p.555-566, 2005.

Ramalho, F.S.; Jesus, F.M.M.; GonZAGA, J.V. Táticas de manejo integrado de pragas em áreas infestadas pelo bicudo-do-algodoeiro. Pesquisa Agropecuária Brasilei$r a$, v.25, n.5, p.677-690, 1990.

RAmiro, Z.A.; FARIA, A.M. DE Levantamento de insetos predadores nos cultivares de algodão bollgard dp90 e convencinal delta pine acala 90. Arquivos do Instituto Biológico, São Paulo, v.73, n.1, p.119-121, 2006. Disponível em: \ttp://www.biologico.sp.gov.br/ARQUIVOS/V73_1/ramiro.PDF>. Acesso em: $5 \mathrm{dez}$. 2006.

Silva, F.M.A.; Fowler, H.G.; Lemos R.N.S. Parasitismo em Lagarta-do-Cartucho, Spodoptera frugiperda (Smith), na Região do Triângulo Mineiro, MG. Anais da Sociedade Entomológica do Brasil, v.26, n.2, p.235-241, 1997.
Silvie, P.; Leroy, T.; Michel, B.; Bournier, J.P. Manual de identificação dos inimigos naturais no cultivo do algodão. Cascavel: Codetec/CIRAD, 2001. 74p. (Boletim Técnico, 35).

Souza, V.P. Dinâmica populacional de Myzus persicae(Sulzer, 1776), Brevicoryne brassicae (Linnaeus, 1758) e Lipaphis erysimi (Kaltenbach, 1843) (Hemiptera: Aphididae) na região de Jaboticabal, SP. 2004. 52p. Dissertação (Mestrado em Agronomia/Entomologia Agrícola) Faculdade de Ciências Agrárias e Veterinárias, Universidade Estadual Paulista, Jaboticabal, 2004. Dis-

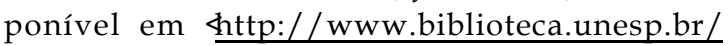
bibliotecadigital/document/get.php/2275/souza vp_me_jab> acesso em: 22 jan. 2007.

Sujil, E.R., LöveI, G.L.; Sétamou, M.; Silvie, P.; Fernandes, M.G.; Dubois, G.S.J.; Almeida, R.P. Non-target and biodiversity impacts on non-target herbivorous pests. In: Hilbeck, A.; ANDow, D.A.; Fontes, E.M.G. (Eds.). Environmental risk assessment of genetically modified organisms volume 2: methodologies for Assessing Bt Cotton in Brazil. Wallingford:CABIPublishing, 2006. p.133-154.

Wilson, L.J.; BaUer, L.R.; Lally D.A. Insecticide induced increases in aphid abundance in cotton. Australian Journal of Entomology, v.38, p.242-243, 1999.

Wilson, L.J.; Sadras, V.O.; Heimoana S.C.; Gibb, D. How to succeed by doing nothing: cotton compensation after stimulated early season pest damage. Crop Science, v.43, p.2125-2134, 2003.

ZAHR, J.H. Biostatiscal analysis. 4.ed. Upper Saddle River: Prentice Hall, 1999. 663p.

Recebido em 25/1/07

Aceito em 5/12/07 